\title{
Prognostic Factors For Intermediate-Risk Atypical Meningiomas Determining Early Postoperative Adjuvant Radiotherapy Versus Active Monitoring After Gross Total Resection
}

\author{
Muhammet Enes Gurses \\ Hacettepe University: Hacettepe Universitesi \\ Hatice Yagmur Zengin \\ Hacettepe University: Hacettepe Universitesi \\ Aysel Shıkhaliyeva \\ Hacettepe University: Hacettepe Universitesi \\ Cengiz Savas Askun \\ METU: Orta Dogu Teknik Universitesi \\ Melike Mut ( $\triangle$ melikem@hacettepe.edu.tr) \\ Hacettepe Universitesi https://orcid.org/0000-0002-9601-9907
}

\section{Research Article}

Keywords: meningioma, atypical meningioma, WHO Grade 2, radiotherapy, gross total resection, prognostic factor

Posted Date: November 1st, 2021

DOI: https://doi.org/10.21203/rs.3.rs-1017992/v1

License: (c) (1) This work is licensed under a Creative Commons Attribution 4.0 International License.

Read Full License 


\section{Abstract \\ Background}

Atypical meningiomas (AMs) constitute $18 \%$ of meningiomas. Predictors of recurrence are still indeterminate, and the timing of RT whether to treat with radiation upfront or at initial recurrence remains controversial, especially after gross total resection (GTR).

\section{Methods}

A retrospective study of AMs with uni-and multivariate analyses was conducted with clinical, surgical, radiological, and histopathological parameters. The prognostic factors associated with increased risk of recurrence were elucidated in the whole series and in the subgroup with GTR only.

\section{Results}

Subtotal resection (STR), skullbase-tentorium localization, no adjuvant RT, and progesterone-negativity caused tumor recurrence in 37 patients with a median follow-up of 48 (2-120) months. Among subgroup of 23 patients GTR only, $30.8 \%$ showed recurrence in a median of 39.65 months. AMs with a preoperative volume $\geq 27.5 \mathrm{~cm}^{3}$ disclosed a significantly higher risk of recurrence (a 9.3 fold increase) than those with $<27.5 \mathrm{~cm}^{3}(66.7 \%$ vs. $14.3 \%$, respectively). Skullbase-tentorium localization and progesterone negativity tend to have higher recurrence rates after GTR.

\section{Conclusions}

Preoperative volume was found to be a prognostic factor for AMs with a cut-off value of $27.5 \mathrm{~cm}^{3}$ for the first time in the literature. Our results disclosed that RT could be delayed with active monitorization after GTR for AMs, which are smaller than $27.5 \mathrm{~cm}^{3}$, not localized in skullbase-tentorium and progesteronepositive. Otherwise, early postop RT would be a safer approach without waiting the recurrence for AMs.

\section{Introduction}

Meningioma is the most common tumor, constituting $39 \%$ of brain and other CNS tumors in adults. Atypical meningiomas (WHO Grade II) are less frequent than benign meningiomas, which are approximately $18 \%$ of all meningiomas (1). Atypical meningiomas (AMs) are complex neoplasms with a wide variety of clinical presentations and morphologies. Histological review of grade II Meningiomas are defined by one or more of the following four criteria according to the 2016 WHO classification: 1) 4-19 mitotic figures/10 HPF or brain invasion. 2) Chordoid or clear cell histological subtype 3) brain infiltration, and 4) three or more of the following five histological features: increased cellularity, a small cell with high 
$\mathrm{N} / \mathrm{C}$ ratio, large and prominent nucleoli, patternless or sheet-like growth, foci of 'spontaneous' or geographic necrosis. The WHO Classification for CNS Tumors, revised in 2016, now includes brain invasion as a single criterion for classifying these tumors as AMs $(2,3)$. AMs have more aggressive behavior and tend to recur around $41-47 \%$ in a 5 -year follow-up (4). Surgery and radiotherapy (RT) are the main therapeutic approaches for AMs (5). Predictors of recurrence are still indeterminate for AMs, and likewise, treatment approaches may differ after surgical resection (6). In case of recurrence, a modality of RT is unequivocally undertaken accompanied by another surgical intervention if feasible. Moreover, gross total resection (GTR) of AMs raises questions regarding the timing of RT; whether to treat with radiation upfront or at initial recurrence remains controversial.

Early postop RT may help reduce tumor regrowth with some side effects like hair loss, fatigue, lethargy, and late toxicities like memory deficits, difficulty in concentration, and other neurocognitive dysfunction. On the other hand, only surgical treatment with active monitoring may carry a higher risk of recurrence, resulting in more aggressive treatment with radiotherapy, surgery, or both. Clinical trials addressing the question had inherent difficulties in randomization due to heterogeneity of both tumor and therapeutic approaches in AMs (7-9).

In our study, we retrospectively analyzed the patients diagnosed with atypical (WHO Grade II) meningioma. We sought to determine which factors affect the clinicians' decision-making process for early adjuvant postoperative RT with the predictors of recurrence. Then, our study focused on AMs with GTR that might harbor good prognostic factors to justify active monitoring of AMs and delaying RT.

\section{Materials And Methods}

We conducted a retrospective analysis of patients harboring AM (WHO Grade II meningioma) treated at Hacettepe University Department of Neurosurgery between the years 2010-2019 and collected the data of 57 patients diagnosed with AM. Patients who did not meet the criteria (patients who received RT at recurrence, any incomplete data sets regarding radiological and pathological work-up, patients lost to follow-up) were excluded. Each patient's treatment characteristics, such as the extent of resection, histopathological findings, follow-up outpatient visits, and adjuvant treatment information, were reported, including sex, age at diagnosis, tumor diameters and location, operative characteristics, molecular findings, postoperative radiotherapy, if any, and duration of follow-up. In the end, 37 patients were included in the study for analysis.

Locations of tumors were divided into the following categories: 1) Convexity; 2) Parasagittal 3) Skullbase-tentorial according to their anatomical location. The extent of resection was described as subtotal resection (STR) (Simpson Grade 4-5) or GTR (Simpson Grade 1-2-3). The tumor resection status was evaluated with early postoperative magnetic resonance imaging (MRI).

Tumors were histopathologically diagnosed as AM per diagnostic criteria of the WHO 2016 classification. The criteria used were being clear cell, or chordoid in morphology; or 4-19 mitotic figures/10 HPF; or brain invasion; or 3 of the following minor criteria (increased cellularity, small cell with high N/C ratio, 
large and prominent nucleoli, patternless or sheet-like growth, foci of 'spontaneous' or geographic necrosis).

The recurrence was described as radiological evidence of tumor regrowth in the case of GTR or progression of the residual tumor in STR cases. Follow-up time was calculated from the time of the first surgical intervention.

An interdisciplinary tumor board was conducted for each patient to obtain the postoperative care recommendations.

\section{Statistical analysis}

Independent groups were compared in terms of numeric parameters by using the Independent samples ttest when the parametric test assumptions were satisfied. In addition, mean \pm standard deviation was represented as descriptive statistics. Otherwise, the Mann-Whitney $U$ test was used with median (minimum value-maximum value) as descriptive statistics. Normality assumption was evaluated using the Shapiro-Wilk normality test. The assumption of homogeneity of group variances was assessed using the Levene test. The independence of the categorical variables was assessed by Fisher's Exact test or Fisher-Freeman-Halton (Generalized Fisher's). The exact test depended on the size of the contingency table. In addition, the one-sample chi-square test was used for evaluating homogeneity in categorical distributions. Variables with P-value equal to or less than 0.20 in the univariate analysis are considered as the candidate variables for multivariate analysis(10) in addition to common confounding factors such as age and gender. Both univariable and multivariable Firth's logistic regression analyses were applied to estimate odds ratios with $95 \%$ confidence intervals to predict the risk of recurrence in general and in the patients who did not receive radiotherapy treatment after gross total resection. In addition, Receiver Operating Characteristics (ROC) Curve Analysis was performed to estimate Area Under the Curve (AUC) for meningioma volume to evaluate the predictive performance of the variable considering the patient's recurrence. Hence, Youden's $J$ index was used to calculate the optimal cut-off point for meningioma volume. IBM SPSS Statistics version 23® for Windows (Armonk, NY: IBM Corp.) was used for all statistical analyses. The level of significance was set at $p<0.05$.

\section{Results}

This analysis included 37 patients with AM. Eleven of 37 patients received adjuvant RT immediately after primary tumor resection without waiting for the recurrence. None of the patients who received early adjuvant RT had recurrence/progression during their follow-up with a median of 48 months (24-84 months). Comparing the characteristics of patients who had early postop RT to those in the active monitoring group, all parameters were similar in clinical, radiological, and histopathological findings except for the extent of resection (Table 1). The neurooncology board was inclined to make decisions for administering early postop RT after STR $(66.7 \%)$ compared to after GTR $(17.9 \%)(p=0.01)$. Even if a statistical significance has not been reached, the patients who received early postop RT were presented 
with more than double the volume ( 20 vs. $43 \mathrm{~cm}^{3}$ ) than one in the follow-up group (Table 1). In our series, STR is the most critical factor in influencing the decision of early postop RT. 
Table 1

Distribution of clinical, radiological and pathological features in 2 groups of atypical meningioma patients who received the RT vs. close monitoring without RT after surgical resection.

\begin{tabular}{|c|c|c|c|c|}
\hline & & Radiotherapy & & \\
\hline & & $\begin{array}{l}\text { Absent } \\
(n=26)\end{array}$ & $\begin{array}{l}\text { Exist } \\
(n=11)\end{array}$ & p \\
\hline Age & & $51.04 \pm 13.961$ & $56 \pm 8.775$ & $0.285^{a}$ \\
\hline Gender & Male & $13(81.3 \%)$ & $3(18.8 \%)$ & $0.285^{b}$ \\
\hline & Female & $13(61.9 \%)$ & $8(38.1 \%)$ & \\
\hline Localization & Skullbase & $12(75.0 \%)$ & $4(25.0 \%)$ & $0.426^{c}$ \\
\hline & Parasagittal & $4(50.0 \%)$ & $4(50.0 \%)$ & \\
\hline & Convexity & 10 (76.9\%) & $3(23.1 \%)$ & \\
\hline Headache & Absent & $16(64 \%)$ & $9(36 \%)$ & $0.279^{b}$ \\
\hline & Exist & $10(83.33 \%)$ & $2(16.67 \%)$ & \\
\hline Preop seizure & Absent & $21(70 \%)$ & $9(30 \%)$ & $1.000^{b}$ \\
\hline & Exist & $5(71.43 \%)$ & $2(28.57 \%)$ & \\
\hline Extent of resection & STR & 3 (33.33\%) & $6(66.67 \%)$ & $0.011^{b, *}$ \\
\hline & GTR & $23(82.14 \%)$ & $5(17.86 \%)$ & \\
\hline Preop tumor volume & & $20(2-127)$ & $43(1-88)$ & $0.658^{d}$ \\
\hline Herniation & Absent & $16(72.73 \%)$ & $6(27.27 \%)$ & $0.728^{b}$ \\
\hline & Exist & $10(66.67 \%)$ & $5(33.33 \%)$ & \\
\hline MRI edema & Absent & $12(85.71 \%)$ & $2(14.29 \%)$ & $0.150^{b}$ \\
\hline & Exist & $14(60.87 \%)$ & $9(39.13 \%)$ & \\
\hline Progesterone & Positive & $13(54.2 \%)$ & $11(45.8 \%)$ & $0.683^{e}$ \\
\hline Pathological brain invasion & Absent & $18(69.23 \%)$ & $8(30.77 \%)$ & $1.000^{b}$ \\
\hline & Exist & $8(72.73 \%)$ & $3(27.27 \%)$ & \\
\hline 4 - 19 mitosis / 10 HPF & Absent & $2(100 \%)$ & $0(0 \%)$ & $1.000^{b}$ \\
\hline & Exist & $24(68.57 \%)$ & $11(31.43 \%)$ & \\
\hline
\end{tabular}




\begin{tabular}{|c|c|c|c|c|}
\hline & & \multicolumn{3}{|l|}{ Radiotherapy } \\
\hline & & $\begin{array}{l}\text { Absent } \\
(n=26)\end{array}$ & $\begin{array}{l}\text { Exist } \\
(n=11)\end{array}$ & 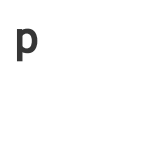 \\
\hline Ki67 & & $5.69 \pm 3.484$ & $5.18 \pm 2.228$ & $0.658^{a}$ \\
\hline \multirow[t]{2}{*}{ Brain invasion } & Absent & $18(69.23 \%)$ & $8(30.77 \%)$ & \multirow[t]{2}{*}{$1.000^{b}$} \\
\hline & Exist & $8(72.73 \%)$ & $3(27.27 \%)$ & \\
\hline \multirow[t]{2}{*}{ Increased cellularity } & Absent & $21(70 \%)$ & $9(30 \%)$ & \multirow[t]{2}{*}{$1.000^{b}$} \\
\hline & Exist & $5(71.43 \%)$ & $2(28.57 \%)$ & \\
\hline \multirow[t]{2}{*}{ Small cells with high $\mathrm{N} / \mathrm{C}$ ratio } & Absent & $14(63.64 \%)$ & $8(36.36 \%)$ & \multirow[t]{2}{*}{$0.466^{b}$} \\
\hline & Exist & $12(80 \%)$ & $3(20 \%)$ & \\
\hline \multirow[t]{2}{*}{ Large-prominent nucleoli } & Absent & $5(83.33 \%)$ & $1(16.67 \%)$ & \multirow[t]{2}{*}{$0.646^{b}$} \\
\hline & Exist & $21(67.74 \%)$ & $10(32.26 \%)$ & \\
\hline \multirow[t]{2}{*}{ Patternless or sheet-like growth } & Absent & $22(68.75 \%)$ & $10(31.25 \%)$ & \multirow[t]{2}{*}{$1.000^{b}$} \\
\hline & Exist & $4(80 \%)$ & $1(20 \%)$ & \\
\hline \multirow[t]{2}{*}{ Foci of necrosis } & Absent & $13(65 \%)$ & $7(35 \%)$ & $0.495^{b}$ \\
\hline & Exist & $13(76.47 \%)$ & $4(23.53 \%)$ & \\
\hline Follow-up time (months) & & $48(2-120)$ & $48(24-84)$ & $0.421^{d}$ \\
\hline
\end{tabular}

Then, we sought to determine the factors associated with recurrence in the whole series of 37 patients and analyzed the clinical, imaging, histopathological prognostic factors, the extent of resection (GTR with early postop RT, GTR without RT, STR with early postop RT, STR without RT) (Table 2). 
Table 2

Clinical and pathological parameter distributions in patient groups whose tumors recur and did not recur during the follow-up period.

\begin{tabular}{|c|c|c|c|c|}
\hline & \multicolumn{3}{|l|}{ Recurrence } \\
\hline & & Absent $(n=26)$ & Exist (n=11) & $p$ \\
\hline \multirow[t]{2}{*}{ Radiotherapy } & Absent & $15(57.69 \%)$ & $11(42.31 \%)$ & \multirow{2}{*}{$0.015^{a}$, * } \\
\hline & Exist & $11(100 \%)$ & $0(0 \%)$ & \\
\hline Age & & $58(32-69)$ & $45(28-76)$ & $0.160^{\mathrm{b}}$ \\
\hline \multirow[t]{2}{*}{ Gender } & Male & $11(68.75 \%)$ & $5(31.25 \%)$ & \multirow[t]{2}{*}{$1.000^{\mathrm{a}}$} \\
\hline & Female & $15(71.43 \%)$ & $6(28.57 \%)$ & \\
\hline \multirow[t]{2}{*}{ Headache } & Absent & $19(76 \%)$ & $6(24 \%)$ & \multirow[t]{2}{*}{$0.443^{a}$} \\
\hline & Exist & $7(58.33 \%)$ & $5(41.67 \%)$ & \\
\hline \multirow[t]{2}{*}{ Seizure } & Absent & $22(73.33 \%)$ & $8(26.67 \%)$ & \multirow[t]{2}{*}{$0.403^{a}$} \\
\hline & Exist & $4(57.14 \%)$ & $3(42.86 \%)$ & \\
\hline \multirow[t]{3}{*}{ Localization } & Skullbase-tentorium & $8(50.0 \%)$ & $8(50.0 \%)$ & \multirow[t]{3}{*}{$0.030^{c, *}$} \\
\hline & Parasagittal & $8(100 \%)$ & $0(0 \%)$ & \\
\hline & Convexity & $10(76.92 \%)$ & $3(23.08 \%)$ & \\
\hline Meningioma volume & & $20(1-117)$ & $28(4-127)$ & $0.384^{b}$ \\
\hline \multirow[t]{2}{*}{ Herniation } & Absent & $16(72.73 \%)$ & $6(27.27 \%)$ & \multirow[t]{2}{*}{$0.728^{a}$} \\
\hline & Exist & $10(66.67 \%)$ & $5(33.33 \%)$ & \\
\hline \multirow[t]{2}{*}{ Sinus invasion } & Absent & $22(70.97 \%)$ & $9(29.03 \%)$ & \multirow[t]{2}{*}{$1.000^{\mathrm{b}}$} \\
\hline & Exist & $4(66.67 \%)$ & $2(33.33 \%)$ & \\
\hline \multirow[t]{2}{*}{ MRI edema } & Absent & $9(64.29 \%)$ & $5(35.71 \%)$ & \multirow[t]{2}{*}{$0.713^{a}$} \\
\hline & Exist & $17(73.91 \%)$ & $6(26.09 \%)$ & \\
\hline Mitotic index & & $4(1-10)$ & $4(0-6)$ & $0.132^{\mathrm{b}}$ \\
\hline Ki67 & & $5(2-15)$ & $5(1-10)$ & $0.316^{b}$ \\
\hline Progesterone receptor & Exist & $20(83.3 \%)$ & $4(16.7 \%)$ & $0.001^{d, *}$ \\
\hline Resection & GTR only & $15(65.2 \%)$ & $8(34.8 \%)$ & $0.281^{\mathrm{a}}$ \\
\hline
\end{tabular}




\begin{tabular}{|c|c|c|c|c|}
\hline & & \multicolumn{3}{|l|}{ Recurrence } \\
\hline & & Absent $(n=26)$ & Exist $(n=11)$ & $p$ \\
\hline & GTR+RT & $5(100.0 \%)$ & $0(0 \%)$ & \\
\hline & STR only & $0(0 \%)$ & $3(100.0 \%)$ & $0.012^{a}$ \\
\hline & STR+RT & $6(100.0 \%)$ & $0(0 \%)$ & \\
\hline 4 - 19 mitotic figures/10 HPF & Absent & $0(0 \%)$ & $2(100 \%)$ & $0.083^{b}$ \\
\hline & Exist & $26(74.29 \%)$ & $9(25.71 \%)$ & \\
\hline Brain invasion & Absent & $18(69.23 \%)$ & $8(30.77 \%)$ & $1.000^{\mathrm{b}}$ \\
\hline & Exist & $8(72.73 \%)$ & $3(27.27 \%)$ & \\
\hline Increased cellularity & Absent & $22(73.33 \%)$ & $8(26.67 \%)$ & $0.403^{b}$ \\
\hline & Exist & $4(57.14 \%)$ & $3(42.86 \%)$ & \\
\hline Small cells with high $\mathrm{N} / \mathrm{C}$ ratio & Absent & $16(72.73 \%)$ & $6(27.27 \%)$ & $0.728^{b}$ \\
\hline & Exist & $10(66.67 \%)$ & $5(33.33 \%)$ & \\
\hline Large and prominent nucleoli & Absent & $4(66.67 \%)$ & $2(33.33 \%)$ & $1.000^{\mathrm{b}}$ \\
\hline & Exist & $22(70.97 \%)$ & $9(29.03 \%)$ & \\
\hline Patternless or sheet-like growth & Absent & $23(71.88 \%)$ & $9(28.13 \%)$ & $0.623^{b}$ \\
\hline & Exist & $3(60 \%)$ & $2(40 \%)$ & \\
\hline Foci of necrosis & Absent & $15(75 \%)$ & $5(25 \%)$ & $0.719^{b}$ \\
\hline & Exist & $11(64.71 \%)$ & $6(35.29 \%)$ & \\
\hline Follow-up time (months) & & $42.38 \pm 23.615$ & $52.73 \pm 33.302$ & $0.290^{\mathrm{e}}$ \\
\hline
\end{tabular}

Univariate Firth's logistic regression analysis showed that early postop RT without waiting for the recurrence is one of the most important factors to prevent the recurrence; no patient showed recurrence after RT ( $p=0.015)$. STR was a significant risk factor for tumor resection, and the recurrence was unequivocally observed in all three patients who underwent STR and received no postop RT ( $p=0.012$ ). Although a statistical significance has not been reached $(p=0.28), 65.2 \%$ of the patients in GTR without early postop RT were recurrence-free during their follow-up were (42.3 \pm 23.6 months). STR caused a 2.4 fold increased risk for recurrence independent of the status of postop RT.

Tumor localization was another significant risk factor associated with tumor recurrence. Skullbasetentorium tumors (50\%) were more likely to recur. The absence of progesterone receptor expression was a 
significant risk factor for the recurrence of AM. In Univariate Firth's logistic regression analysis, progesterone negative tumors carried 5.26 times the risk for recurrence than progesterone positive tumors. The risk is significantly increased to $6.3(1,26-46,79)$ in Multivariate Firth's logistic regression analysis.

For AMs, a high risk of recurrence was observed in one of the following factors existence: absence of early postoperative RT, skullbase-tentorium localization; STR, and progesterone-negativity (Table 2).

Our first results raised a question if GTR were accomplished for all AMs, which prognostic factors would possibly delay RT. Then, among the patients who underwent GTR $(n=28)$, we excluded the patients who received early postop RT $(n=5)$ and analyzed the remaining 23 patients with GTR adjuvant RT. Among these 23 patients, eight patients (30.8\%) showed recurrence after the GTR in a median of 39.65 months follow-up. The univariate analysis demonstrated that the only factor significantly affecting the recurrence after GTR was the preoperative volume $(p=0.028)$. A ROC analysis for determining a cut-off point of the volume associated with recurrence revealed $27.5 \mathrm{~cm}^{3}$ (Figure 1). Patients harboring AM with a preoperative volume of $27.5 \mathrm{~cm}^{3}$ or larger disclosed a significantly higher risk of recurrence than those with smaller volumes even though they had undergone a GTR for their tumors ( $14.3 \%$ vs. $66.7 \%$ recurrence rate). Twelve tumors smaller than $27.5 \mathrm{~cm}^{3}$ revealed no recurrence after GTR during their follow-up (median 40.75 months). Tumor volume $\geq 27.5 \mathrm{~cm}^{3}$ had a 9.3 fold increased risk compared to small tumor volume for recurrence. After adjusting the age and gender effect on the recurrence of the patients in GTR without RT, volume was still critical in the multivariate Firth's Logistic Regression analysis, where tumor volume $\geq 27.5 \mathrm{~cm}^{3}$ had a 7.7 fold increase risk compared to smaller volumes. Even if statistical significance was not attained, probably due to the small sample size, tumors localized to skullbase-tentorium and having no progesterone receptor expression showed higher recurrence rates (Table 3). 
Table 3

Clinical and pathological parameter distributions in 23 patients who did not receive radiotherapy after GTR.

\begin{tabular}{|c|c|c|c|c|}
\hline & & Recurrence & & \\
\hline & & Absent $(n=15)$ & Exist $(n=8)$ & $\mathbf{p}$ \\
\hline Age & & $58(32-64)$ & $48.5(28-76)$ & $0.776 a$ \\
\hline Gender & Male & $8(80 \%)$ & $2(20 \%)$ & $0.379 b$ \\
\hline & Female & $7(53.85 \%)$ & $6(46.15 \%)$ & \\
\hline Localization & Skullbase-tentorium & $4(40 \%)$ & $6(60 \%)$ & $0.105 c$ \\
\hline & Parasagittal & $4(100 \%)$ & $0(0 \%)$ & \\
\hline & Convexity & $7(77.78 \%)$ & $2(22.22 \%)$ & \\
\hline Meningioma volume & & $16(2-117)$ & $50.5(8-127)$ & $0.028 a{ }^{*}{ }^{*}$ \\
\hline Meningioma volume & $<27.5 \mathrm{~mm}^{3}$ & $12(85.7 \%)$ & $2(14.3 \%)$ & $0.023 b^{*}$ \\
\hline & $\geq 27.5 \mathrm{~mm}^{3}$ & $3(33.3 \%)$ & $6(66.7 \%)$ & \\
\hline Headache & Absent & $10(71.43 \%)$ & $4(28.57 \%)$ & $0.657 b$ \\
\hline & Exist & $5(55.56 \%)$ & $4(44.44 \%)$ & \\
\hline Seizure & Absent & $13(72.22 \%)$ & $5(27.78 \%)$ & $0.297 b$ \\
\hline & Exist & $2(40 \%)$ & $3(60 \%)$ & \\
\hline Herniation & Absent & $10(76.92 \%)$ & $3(23.08 \%)$ & $0.221 b$ \\
\hline & Exist & $5(50 \%)$ & $5(50 \%)$ & \\
\hline MRI edema & Absent & $7(77.78 \%)$ & $2(22.22 \%)$ & $0.400 \mathrm{~b}$ \\
\hline & Exist & $8(57.14 \%)$ & $6(42.86 \%)$ & \\
\hline Ki67 & & $6.53 \pm 3.720$ & $5.38 \pm 2.774$ & $0.450 \mathrm{~d}$ \\
\hline Mitotic index & & $4.27 \pm 1.223$ & $3.50 \pm 1.069$ & $0.151 \mathrm{e}$ \\
\hline 4 - 19 mitotic figures/10 HPF & Absent & $0(0 \%)$ & $1(100 \%)$ & $0.348 b$ \\
\hline & Exist & $15(68.18 \%)$ & $7(31.82 \%)$ & \\
\hline Brain invasion & Absent & $10(66.67 \%)$ & $5(33.33 \%)$ & $1.000 \mathrm{~b}$ \\
\hline & Exist & $5(62.5 \%)$ & $3(37.5 \%)$ & \\
\hline
\end{tabular}




\begin{tabular}{|c|c|c|c|c|}
\hline & & \multicolumn{3}{|l|}{ Recurrence } \\
\hline & & Absent $(n=15)$ & Exist $(n=8)$ & p \\
\hline \multirow[t]{2}{*}{ Increased cellularity } & Absent & $13(72.22 \%)$ & $5(27.78 \%)$ & \multirow[t]{2}{*}{$0.297 \mathrm{~b}$} \\
\hline & Exist & $2(40 \%)$ & $3(60 \%)$ & \\
\hline \multirow[t]{2}{*}{ Small cells with high $\mathrm{N} / \mathrm{C}$ ratio } & Absent & $8(72.73 \%)$ & $3(27.27 \%)$ & \multirow[t]{2}{*}{$0.667 b$} \\
\hline & Exist & $7(58.33 \%)$ & $5(41.67 \%)$ & \\
\hline \multirow[t]{2}{*}{ Large and prominent nucleoli } & Absent & $3(75 \%)$ & $1(25 \%)$ & \multirow[t]{2}{*}{$1.000 \mathrm{~b}$} \\
\hline & Exist & $12(63.16 \%)$ & $7(36.84 \%)$ & \\
\hline \multirow[t]{2}{*}{ Patternless or sheet-like growth } & Absent & $13(68.42 \%)$ & $6(31.58 \%)$ & \multirow[t]{2}{*}{$0.589 \mathrm{~b}$} \\
\hline & Exist & $2(50 \%)$ & $2(50 \%)$ & \\
\hline \multirow[t]{2}{*}{ Foci of necrosis } & Absent & $8(66.67 \%)$ & $4(33.33 \%)$ & \multirow[t]{2}{*}{$1.000 \mathrm{~b}$} \\
\hline & Exist & $7(63.64 \%)$ & $4(36.36 \%)$ & \\
\hline Progesterone & Positive & $9(75 \%)$ & $3(25 \%)$ & $0.083 d$ \\
\hline Follow-up time (months) & & $36(5-108)$ & $54(2-84)$ & $0.325 a$ \\
\hline
\end{tabular}

\section{Discussion}

Atypical meningiomas carry a 7 to 8 fold increase in the risk of recurrence at five years compared to WHO grade I meningioma (11). In our series, when all patients were taken into consideration, as shown in Table 2 , four prognostic factors were found to be statistically significant in the postoperative recurrence rate: Extent of resection, adjuvant RT, tumor localization, and progesterone expression.

Surgical resection is the first step in the treatment algorithm for the treatment of meningiomas. The impact of GTR on prognosis is well-grounded, given established literature revealing a complete tumor resection under relatively safe conditions remains an effective treatment technique and remains the mainstay of the approach to minimize the risk of recurrence and increase survival compared to STR in AMs (12-18). In our study, GTR was found to be one of the most important factors in the recurrence of AMs; $100 \%$ of tumors with STR only recurred as opposed to $34.8 \%$ of tumors with GTR only in similar follow-up times (Table 2).

Some studies present the active monitoring after GTR of AMs as a safe alternative to RT given the existing knowledge of no statistically significant impact on overall survival, but a possible role on progression-free survival (PFS) $(15,19)$ Although the role of surgical resection, particularly GTR is 
unequivocal in the management of AMs and late-term complications pertained to radiation-induced toxicity are known; recurrence remains a confrontational fact for AMs even after GTR. In our series, no patients had recurrence after RT (Table 2). However, the most important question still resides about the timing of RT. Early adjuvant radiation has been shown to improve long-term control $(20,21)$. Given the elevated risk of tumor recurrence with residual disease after surgery, adjuvant RT is a commonly accepted practice for AMs with STR (6). Park et al. recommend adjuvant therapy for AMs after STR (22). A clinical trial, The RTOG 0539 study, classified meningiomas into three risk groups: The low-risk group with new WHO grade 1 meningiomas after GTR or STR, the intermediate-risk group with recurrent WHO grade 1 meningiomas after GTR or STR, and WHO grade 2 meningiomas after GTR, and the high-risk group with WHO grade 3 meningioma and any recurrent WHO grade 2 meningioma, or a new WHO grade 2 meningioma after STR resection. The primary endpoint of the study, which is 3-year PFS was compared with historical controls (3-year PFS: 70\% following GTR alone and 90\% with GTR + RT). The 3-year overall survival rate for the intermediate-risk group was $96 \%$. Still, the results represented rates obtained from treatment of newly diagnosed AMs with GTR and recurrent WHO Grade I meningioma irrespective of resection extent $(23,24)$. Unsurprisingly, in our series, STR of AMs without postop RT resulted in recurrence as correlated well with the findings of the high-risk group for the RTOG 0539 trial. Our intermediate-risk group, AMs with GTR revealed $38.4 \%$ recurrence in $52.73 \pm 33.302$ months, which was longer than the 3-year follow-up time of the RTOG 0539 study (Table 2).

Two other factors were found to be significantly associated with recurrence of AMs besides the extent of resection and RT: Tumor localization and progesterone expression. AMs localized in skullbase-tentorium had a higher recurrence rate compared to tumors localized in convexity or parasagittal regions. Moreover, progesterone-negative tumors were correlated with recurrence. (Table 2).

Adjuvant therapy for high-risk group AMs with STR is commonly accepted; nevertheless, the role of adjuvant therapy in patients who have had GTR for AM is still debated in the intermediate group, and several studies reflected conflicting reports in the literature $(20-22,25-27)$. Early postoperative radiotherapy after resection of AM is increasingly being promoted, based on a single institutional series $(24,28-30)$. These previous retrospective studies of early adjuvant RT after surgical resection of WHO grade II meningioma have arrived at conflicting conclusions on whether adjuvant radiotherapy reduces recurrence and leads to overall survival benefit. Even if RTOG 0539 proposed the use of postoperative RT for newly diagnosed WHO Grade II regardless of the extent of resection $(23,24)$, surgical series do not necessarily agree with this conclusion $(22,31-34)$. Some studies compared the patients who received early postop adjuvant RT with those with salvage RT at their recurrences after GTR. Momin et al. found $26.4 \%$ of recurrence that required salvage RT after GTR. Although PFS was worse for the observation group compared to the early adjuvant RT group (PFS at 3 and 5 years after observation was $75.1 \%$, $65.6 \%$, and after adjuvant RT was $86.1 \%$ and $5,9.2 \%$, respectively), patients who underwent observation with salvage radiation treatment had significantly longer radiation failure-free free survival (3-, 5-, and 10year radiation failure-free survival rates were $97.7 \%, 90.3 \%$, and $87.9 \%$, respectively). The crucial question that remains to be answered is to reveal bad prognostic factors necessitating early postoperative adjuvant RT without waiting for the recurrence after GTR of AMs. In a series of 108 patients, Aghi et al. 
(20) found a $28 \%$ recurrence rate of AMs after GTR; and most recurrences occurred within five years after resection. In their study, factors predicting worse prognosis were older age, sheeting, and prominent nucleoli (20). In Komotar's series, $41 \%$ of patients who did not undergo postoperative radiotherapy after GTR showed recurrence. Residual tumor, parafalcine/parasagittal location, peritumoral edema, and a MI > 7 were all independently associated with early recurrence (35). Patients with early recurrence had worse neurological outcomes (36). If waited enough, a recurrence is unavoidable for all AMs as most recurrences occur in 5 years after GTR of AMs. However, we sought to determine factors to create a propensity towards early recurrence after GTR. In our series, preoperative tumor volume was the only statistically significant factor that affected the recurrence after GTR. The ROC analysis revealed a cut-off point for the volume, and any tumor greater than $27.5 \mathrm{~cm}^{3}$ had a higher recurrence rate $(66.7 \%)$, and the risk of recurrence was 7.2 times higher in that group. On the contrary, 12 patients in the GTR group who had tumors smaller than $27.5 \mathrm{~cm}^{3}$ revealed no recurrence during their follow-up (9-108 months, median 40.75 months) (Table 3). Even if a statistical significance was not reached, probably due to small sample size; skullbase-tentorium localization, seizure at presentation, and lack of progesterone receptor expression could be predisposing factors for early recurrence (Table 3).

\section{Limitation}

The primary limitation of this study is its retrospective, nonrandomized design. The possible selection bias by different clinicians may favor one treatment as opposed to the other. We only analyzed the radiological evidence of recurrence; we did not compare the treatment complications, quality of life measurements, neurocognitive evaluation, and failure patterns. Moreover, the median follow-up was 48 months for the whole cohort; however, when we looked at the subgroups of the GTR cohort, the recurrence-free group had a median of 36 (5-108) months follow-up in comparison to 54 (2-84) months for the recurrent group although this was not significantly different. We did not include any molecular or genetic signatures of meningiomas to predict the recurrence pattern. We wanted to make a prognostic scale, but our number was limited for statistical validation of each parameter. Further validation will be possible through the results from the randomized trials with larger numbers of patients.

\section{Conclusion}

Clinicians tend to give early postop RT to patients with large tumors and after STR. The most important factors associated with recurrence in AMs are tumor localization, STR, absence of postop RT, and negative progesterone expression. Even if GTR is achieved, some factors may cause meningiomas to recur. Our analysis showed that the most crucial factor is preop tumor volume, and if the volume was higher than $27.5 \mathrm{~cm}^{3}, 2$ out of 3 patients would have a tumor recurrence within three years. Skullbasetentorium localization and progesterone negativity were correlated with the higher recurrence rates after GTR of AMs, while significance was not reached, probably due to the small sample size. 
Our results disclosed for the first time that RT could be delayed with active monitorization if AMs are smaller than $27.5 \mathrm{~cm}^{3}$, with GTR, not localized in skullbase-tentorium and progesterone positive. Otherwise, early postop RT would be a safer approach for tumors larger than $27.5 \mathrm{~cm}^{3}$, localized in skullbase-tentorium, after STR, and with no progesterone expression.

\section{Abbreviations}

AMs = Atypical meningiomas

GTR $=$ Gross total resection

$\mathrm{MRI}=$ Magnetic resonance imaging

RT = Radiotherapy

STR = Subtotal resection

PFS = Progression free survival

\section{Declarations}

Conflict of Interest

The authors have no personal, financial, or institutional interest in materials or devices described in this article.

\section{Disclosure of Funding}

None.

\section{Author Contribution}

All authors contributed to the study conception and design. Material preparation, data collection and analysis were performed by MEG, AS, MM. Statistical analysis was done by HYZ and CSA. The first draft of the manuscript was written by MEG and MM and all authors commented on previous versions of the manuscript. Critical assessment was done by MM. All authors read and approved the final manuscript.

\section{Data Availability}

All requests for raw and analyzed data and materials are promptly reviewed by the corresponding author, Dr. Melike Mut, to verify if the request is subject to any intellectual property or confidentiality obligations. Patient-related data not included in the paper might be subject to patient confidentiality and will be made available upon reasonable request for academic use and within the limitations of the provided informed 
consent by the corresponding author upon acceptance. Every request will be reviewed by the institutional review board of Hacettepe University; the researcher will need to sign a data access agreement with Hacettepe University after approval.

\section{Ethics}

Ethical approval was obtained from the Hacettepe University Ethics Committee (Hacettepe University, Non-Interventional Ethics Committee, Evaluation Date: 09.06.2020, No: GO 20/505, Decision No: 2020/12$60)$.

\section{References}

1. Ostrom QT, Cioffi G, Waite K, Kruchko C, Barnholtz-Sloan JS (2021) CBTRUS Statistical Report: Primary Brain and Other Central Nervous System Tumors Diagnosed in the United States in 20142018. Neuro Oncol 23(12 Suppl 2):iii1-iii105

2. Louis DN, Perry A, Reifenberger G, von Deimling A, Figarella-Branger D, Cavenee WK et al (2016) The 2016 World Health Organization Classification of Tumors of the Central Nervous System: a summary. Acta Neuropathol 131(6):803-820

3. Rogers L, Gilbert M, Vogelbaum MA (2010) Intracranial meningiomas of atypical (WHO grade II) histology. J Neurooncol 99(3):393-405

4. Da Broi M, Borrelli P, Meling TR (2021) Predictors of Survival in Atypical Meningiomas.Cancers (Basel). ; 13(8)

5. Rydzewski NR, Lesniak MS, Chandler JP, Kalapurakal JA, Pollom E, Tate MC et al (2018) Gross total resection and adjuvant radiotherapy most significant predictors of improved survival in patients with atypical meningioma. Cancer 124(4):734-742

6. Rogers L, Barani I, Chamberlain M, Kaley TJ, McDermott M, Raizer J et al (2015) Meningiomas: knowledge base, treatment outcomes, and uncertainties. A RANO review. J Neurosurg 122(1):4-23

7. Hardesty DA, Wolf AB, Brachman DG, McBride HL, Youssef E, Nakaji P et al (2013) The impact of adjuvant stereotactic radiosurgery on atypical meningioma recurrence following aggressive microsurgical resection. J Neurosurg 119(2):475-481

8. Sherratt FC, Brown SL, Haylock BJ, Francis P, Hickey H, Gamble C et al (2020) Challenges Conveying Clinical Equipoise and Exploring Patient Treatment Preferences in an Oncology Trial Comparing Active Monitoring with Radiotherapy (ROAM/EORTC 1308). Oncologist 25(4):e691-e700

9. Shepard MJ, Xu Z, Kearns K, Li C, Chatrath A, Sheehan K et al (2021) Stereotactic Radiosurgery for Atypical (World Health Organization II) and Anaplastic (World Health Organization III) Meningiomas: Results From a Multicenter, International Cohort Study. Neurosurgery 88(5):980-8

10. Heine JJ, Land WH, Egan KM (2011) Statistical learning techniques applied to epidemiology: a simulated case-control comparison study with logistic regression. BMC Bioinformatics 12:37 
11. Esiri M (2000) Russell and Rubinstein's pathology of tumors of the nervous system. Sixth edition. J Neurol Neurosurg Psychiatry 68(4):538D

12. Goldbrunner R, Minniti G, Preusser M, Jenkinson MD, Sallabanda K, Houdart E et al (2016) EANO guidelines for the diagnosis and treatment of meningiomas. Lancet Oncol 17(9):e383-e391

13. Li D, Jiang P, Xu S, Li C, Xi S, Zhang J et al (2019) Survival impacts of extent of resection and adjuvant radiotherapy for the modern management of high-grade meningiomas. $J$ Neurooncol 145(1):125-134

14. Hammouche S, Clark S, Wong AH, Eldridge P, Farah JO (2014) Long-term survival analysis of atypical meningiomas: survival rates, prognostic factors, operative and radiotherapy treatment. Acta Neurochir (Wien) 156(8):1475-1481

15. Graffeo CS, Leeper HE, Perry A, Uhm JH, Lachance DJ, Brown PD et al (2017) Revisiting Adjuvant Radiotherapy After Gross Total Resection of World Health Organization Grade II Meningioma. World Neurosurg 103:655-663

16. Mair R, Morris K, Scott I, Carroll TA (2011) Radiotherapy for atypical meningiomas. J Neurosurg 115(4):811-9

17. Champeaux C, Houston D, Dunn L (2017) Atypical meningioma. A study on recurrence and diseasespecific survival. Neurochirurgie 63(4):273-281

18. Masalha W, Heiland DH, Franco P, Delev D, Haaker JG, Schnell O et al (2018) Atypical meningioma: progression-free survival in 161 cases treated at our institution with surgery versus surgery and radiotherapy. J Neurooncol 136(1):147-154

19. Simonetti G, Silvani A, Tramacere I, Farinotti M, Legnani F, Pinzi V et al (2021) Long term follow up in 183 high grade meningioma: A single institutional experience. Clin Neurol Neurosurg 207:106808

20. Aghi MK, Carter BS, Cosgrove GR, Ojemann RG, Amin-Hanjani S, Martuza RL et al (2009) Long-term recurrence rates of atypical meningiomas after gross total resection with or without postoperative adjuvant radiation. Neurosurgery 64(1):56-60. discussion

21. Bagshaw HP, Burt LM, Jensen RL, Suneja G, Palmer CA, Couldwell WT et al (2017) Adjuvant radiotherapy for atypical meningiomas. J Neurosurg 126(6):1822-8

22. Park HJ, Kang HC, Kim IH, Park SH, Kim DG, Park CK et al (2013) The role of adjuvant radiotherapy in atypical meningioma. J Neurooncol 115(2):241-7

23. Rogers CL, Won M, Vogelbaum MA, Perry A, Ashby LS, Modi JM et al (2020) High-risk Meningioma: Initial Outcomes From NRG Oncology/RTOG 0539. Int J Radiat Oncol Biol Phys 106(4):790-9

24. Rogers L, Zhang P, Vogelbaum MA, Perry A, Ashby LS, Modi JM et al (2018) Intermediate-risk meningioma: initial outcomes from NRG Oncology RTOG 0539. J Neurosurg 129(1):35-47

25. Durand A, Labrousse F, Jouvet A, Bauchet L, Kalamarides M, Menei P et al (2009) WHO grade II and III meningiomas: a study of prognostic factors. J Neurooncol 95(3):367-375

26. Kaur G, Sayegh ET, Larson A, Bloch O, Madden M, Sun MZ et al (2014) Adjuvant radiotherapy for atypical and malignant meningiomas: a systematic review. Neuro Oncol 16(5):628-636 
27. Stessin AM, Schwartz A, Judanin G, Pannullo SC, Boockvar JA, Schwartz TH et al (2012) Does adjuvant external-beam radiotherapy improve outcomes for nonbenign meningiomas? A Surveillance, Epidemiology, and End Results (SEER)-based analysis. J Neurosurg 117(4):669-675

28. Paix A, Waissi W, Antoni D, Adeduntan R, Noel G (2017) Visceral and bone metastases of a WHO grade 2 meningioma: A case report and review of the literature. Cancer Radiother 21(1):55-59

29. Bernat AL, Oyama K, Hamdi S, Mandonnet E, Vexiau D, Pocard M et al (2015) Growth stabilization and regression of meningiomas after discontinuation of cyproterone acetate: a case series of 12 patients. Acta Neurochir (Wien) 157(10):1741-6

30. Jenkinson MD, Javadpour M, Haylock BJ, Young B, Gillard H, Vinten J et al (2015) The ROAM/EORTC-1308 trial: Radiation versus Observation following surgical resection of Atypical Meningioma: study protocol for a randomised controlled trial. Trials 16:519

31. Pearson BE, Markert JM, Fisher WS, Guthrie BL, Fiveash JB, Palmer CA et al (2008) Hitting a moving target: evolution of a treatment paradigm for atypical meningiomas amid changing diagnostic criteria. Neurosurg Focus 24(5):E3

32. Sankila R, Kallio M, Jaaskelainen J, Hakulinen T (1992) Long-term survival of 1986 patients with intracranial meningioma diagnosed from 1953 to 1984 in Finland. Comparison of the observed and expected survival rates in a population-based series. Cancer 70(6):1568-1576

33. Wang YC, Chuang CC, Wei KC, Chang CN, Lee ST, Wu CT et al (2016) Long Term Surgical Outcome and Prognostic Factors of Atypical and Malignant Meningiomas. Sci Rep 6:35743

34. Cho M, Joo JD, Kim IA, Han JH, Oh CW, Kim CY (2017) The Role of Adjuvant Treatment in Patients with High-Grade Meningioma. J Korean Neurosurg Soc 60(5):527-533

35. Komotar RJ, lorgulescu JB, Raper DM, Holland EC, Beal K, Bilsky MH et al (2012) The role of radiotherapy following gross-total resection of atypical meningiomas. J Neurosurg 117(4):679-686

36. Budohoski KP, Clerkin J, Millward CP, O'Halloran PJ, Waqar M, Looby S et al (2018) Predictors of early progression of surgically treated atypical meningiomas. Acta Neurochir (Wien) 160(9):1813-1822

\section{Figures}




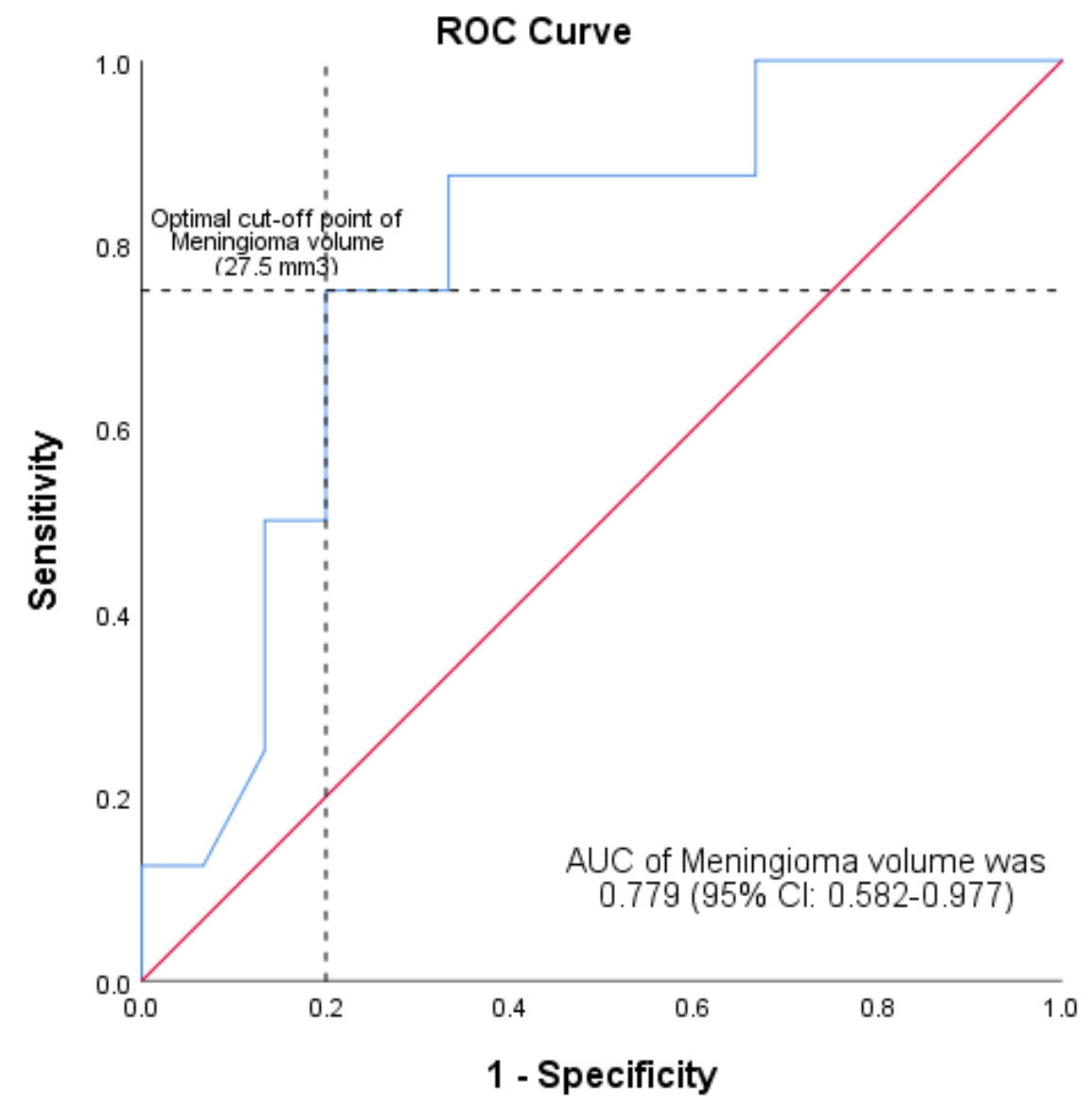

Figure 1

Determination of a cut-off value for preop tumor volume for predicting recurrence in the patients in GTR only group (ROC Curve analysis; Area under curve was estimated $77.9 \%$ (95\% Cl: 0.582-0.977) and it was significant at $0.05(p=0.031)$. Cut-off of preop tumor volume was estimated at $27.5 \mathrm{~cm} 3$ according to the maximum Youden's $\mathrm{J}$ Index with $75 \%$ sensitivity and $80 \%$ specificity with a positive and negative predictive values of $66.7 \%$ and $85.7 \%$, respectively where the prevalence of the recurrence was $34.8 \%$ ). 